\title{
Association between time-related work factors and dietary behaviors: results from the Japan Environment and Children's Study (JECS)
}

Rie Tanaka ${ }^{1}$, Mayumi Tsuji ${ }^{1 *}$, Koichi Kusuhara ${ }^{2,3}$, Toshihiro Kawamoto ${ }^{1}$ and Japan Environment and Children's Study Group

\begin{abstract}
Background: Few studies have examined the association of workhours and shift work (referred to here as "time-related work factors") with dietary behaviors. We aimed to investigate this association, as well as the dietary behaviors among individuals with occupations characterized by time-related work factors.

Methods: A cross-sectional study was performed using data from the Japan Environment and Children's Study. The study included 39,315 working men. Dietary behaviors (i.e., skipping breakfast, eating out, eating instant food, overeating, and eating fast) were assessed with a self-reported information from the Food Frequency Questionnaire. Logistic regression analysis was conducted to examine the associations of time-related work factors with dietary behaviors and dietary behavior tendencies among those in occupations characterized by long workhours and/or shift work.

Results: Long workhours were associated with high frequencies of skipping breakfast, eating out, eating instant food, overeating, and eating fast. The frequency of having shift work was associated with high frequencies of skipping breakfast, eating out, and eating instant food. Several occupations involving long workhours and/or shift work showed specific dietary behaviors; in some occupations, the level of significance changed after adjusting for time-related work factors in addition to other potential confounding factors.

Conclusions: Time-related work factors may help explain workers' dietary behaviors. Long workhours and shift work may lead to poor dietary behaviors. Other factors influenced by occupation itself, such as food environment, may also influence workers' dietary behaviors. Workhours and/or shift work, and these other work factors, should be given attention in workplace health promotion.
\end{abstract}

Keywords: Workhours, Shift work, Occupation, Dietary behaviors

\section{Background}

The association between working conditions and health has been widely recognized. Particularly, time-related work factors, such as workhours and shift work, have been reported to be associated with health issues, including obesity [1], metabolic syndrome [2], and cardiovascular

\footnotetext{
* Correspondence: tsuji@med.uoeh-u.ac.jp

${ }^{1}$ Department of Environmental Health, School of Medicine, University of Occupational and Environmental Health, 1-1 Iseigaoka, Yahatanishi-ku, Kitakyushu, Fukuoka 807-8555, Japan

Full list of author information is available at the end of the article
}

disease [3]. It is crucial to develop an appropriate approach for shift workers and those working long hours to prevent diseases and promote health.

The association between workhours/shift work and health may be partially attributed to workers' dietary behaviors. According to a previous study conducted in various EU countries, irregular workhours was the most frequently reported barrier for healthy eating [4]. Another study including young adults showed that men working more than $40 \mathrm{~h}$ per week were more likely to report time-related barriers to healthy eating, such as

(c) The Author(s). 2018 Open Access This article is distributed under the terms of the Creative Commons Attribution 4.0 International License (http://creativecommons.org/licenses/by/4.0/), which permits unrestricted use, distribution, and reproduction in any medium, provided you give appropriate credit to the original author(s) and the source, provide a link to the Creative Commons license, and indicate if changes were made. The Creative Commons Public Domain Dedication waiver (http://creativecommons.org/publicdomain/zero/1.0/) applies to the data made available in this article, unless otherwise stated. 
"too rushed in the morning to eat a healthy breakfast" and "eating healthy meals takes too much time" [5]. The association between shift work and irregular eating patterns has also been well documented [6].

Dietary behaviors associated with time-related work factors can vary across occupations; thus, knowledge of differences in dietary behaviors between occupations is necessary to make progress in workplace health promotion. Few studies, however, have examined the differences in dietary behaviors between occupations. Relatively poor dietary behaviors have been observed in specific occupations, including among health professionals (physicians [7], nurses [8]), service workers [9], transportation workers [9], and laborers [9]. The exact cause of unhealthy dietary behaviors remains unknown.

Therefore, we hypothesized that the presence of poor dietary behaviors among specific occupations could be attributed to time-related work factors (referred to here as "workhours" and "shift work"). The present study focused on male workers; men's diets may be more likely to be affected by time-related work factors than women's diets. According to a previous study in Europe, men reported "irregular workhours" more frequently as a barrier to healthy eating than women [4]. Gender differences in diet, such as nutrition knowledge [10], attitude [10], behavior [10], and dietary pattern [11], have also been reported previously; for example, one study in Japan reported that compared to women, men showed some dietary patterns, such as lower score for "high-bread and low-rice" and "vegetable" and higher score for "high-meat and low-fish" [11].

The aims of this study were as follows: to provide an overview of workers' dietary behaviors according to their workhours and presence of shift work and to examine their dietary behaviors according to the occupations involving working long hours and/or shift work.

\section{Methods}

\section{Study design}

This study was based on baseline data from the Japan Environment and Children's Study (JECS) (jecs-ag-20160424), which was released in June 2016 [12]. The JECS was designed to investigate the influence of environmental factors on children's health. From the 15 regional centers located across Japan, more than 100,000 pregnant women (mothers) were recruited to the JECS from January 2011 to March 2014, with optional participation being extended to their partners (fathers). The JECS was approved by the Institutional Review Board of the Japan National Institute for Environmental Studies (Approval number: 2017-002) and the Ethics Committees of all participating institutions. The study was conducted in accordance with the Declaration of Helsinki and other national regulations. Written informed consent was obtained from all study participants. Details on the study protocol have been reported previously $[13,14]$.

\section{Study participants}

Information on workhours, shift work, and occupations were obtained from self-administered questionnaires provided to male participants (fathers). Information on partners' occupation (mothers' occupation) was obtained from self-administered questionnaires provided to female participants (mothers) during their first trimester. Information about household income, educational level (fathers' education), and partners' educational level (mothers' education) were obtained from self-administered questionnaires provided to female participants (mothers) during the second or third trimester of their pregnancy. Participants (fathers) who reported their occupations as "students," "househusbands," "unemployed," or "workers not otherwise classifiable" and those with missing questionnaire data were excluded. Finally, 39,315 men were included in the analysis. The flowchart of the selection process is shown in Fig. 1.

\section{Dietary behaviors}

Participants' dietary intakes were assessed using the Food Frequency Questionnaire (FFQ) that was used in the Japan Public Health Center-Based Prospective Study for the Next Generation and has been validated previously $[14,15]$. The following dietary behaviors were assessed using five questions from the FFQ: "How often do you eat breakfast?"; "How often do you eat out?"; "How often do you eat instant food?"; "Do you tend to overeat?"; and "Do you tend to eat fast?"

Response options regarding eating breakfast, eating out, and eating instant food were as follows: "less than once a month," "one to three times per month," "one to two times per week," "three to four times per week," "five to six times per week," and "every day." The response options regarding eating out and eating instant food were categorized into "less than once a month," "one to three times per month", and "one to two times per week" vs "three to four times per week," "five to six times per week," and "every day." The response options regarding eating breakfast were categorized into "every day" vs "less than once a month," "one to three times per month," "one to two times per week," "three to four times per week," and "five to six times per week" (hereinafter called "skipping breakfast"). Response options regarding overeating and eating fast were "no" vs "yes."

\section{Time-related work factors: workhours and shift work}

The number of weekly workhours was calculated from the answers to the questions "How many hours do you work per day?" and "How many days do you work per week?" Accordingly, workhours were categorized into 


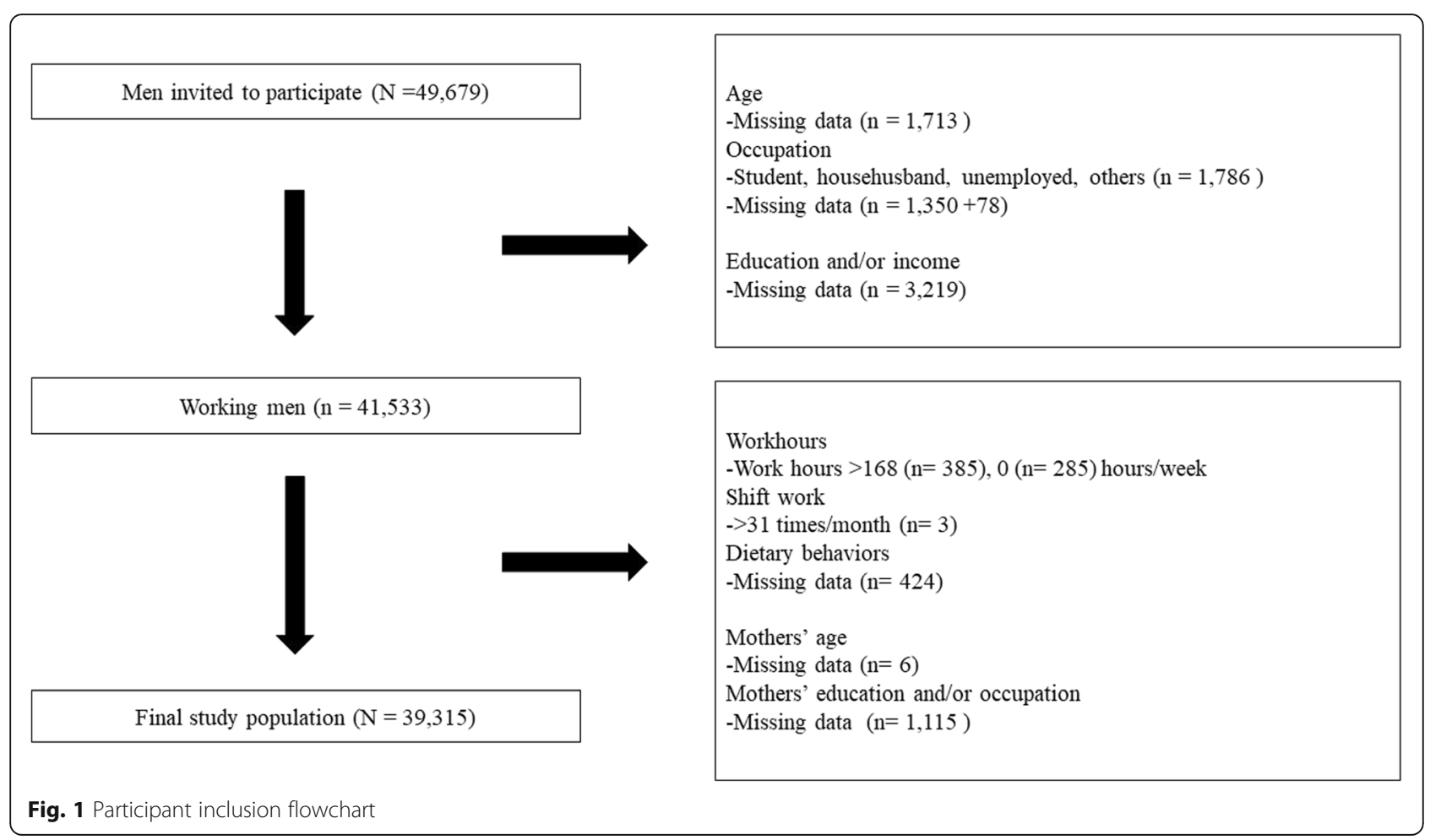

six groups: equal to or less than $40 \mathrm{~h} ;>40$, $\leqq 45 \mathrm{~h} ;>45$, $\leqq 50 \mathrm{~h} ;>50, \leqq 55 \mathrm{~h} ;>55$, $65 \mathrm{~h}$; and more than $65 \mathrm{~h}$ per week. Information on shift work was assessed using the question: "How often do you have shifts other than the day shift?" Based on the responses, the frequency of shift work was categorized into three groups: no (with "zero" as the answer), $>0, \leqq 8$ times, and more than 8 times per month.

\section{Socioeconomic factors}

Participants' educational levels and mothers' educational levels were categorized into junior high school, high school, higher professional school, professional school, junior college, university, and graduate school. Their annual income was categorized into $<2$ million yen, 2.0-3.9 million yen, 4.0-5.9 million yen, 6.0-7.9 million yen, 8.09.9 million yen, 10.0-11.9 million yen, 12.0-14.9 million yen, 15.0-19.9 million yen, and $\geq 20$ million yen. Participants' occupation was classified using the Japanese Occupational Classification (Rev. 5, December 2009) [16], which contains 12 major groups of workers: administrative and managerial; professional and engineering; clerical; sales; service; security; agricultural, forestry, and fishery; manufacturing; transport and machine operation; construction and mining; carrying, cleaning, packaging, and related work; and workers not classifiable by occupation (who were not included in the present analysis). Furthermore, occupation was classified into smaller and more specific groups using the more detailed classification based on the Minor Groups or Unit Groups of the Japanese Standard Occupational Classification (Rev. 5, December 2009) [16, 17]. This study used the latter classification. Small groups comprising less than $1.0 \%$ of all participants were integrated into other groups or unified within each major group. For example, within the "administrative and managerial workers" group, smaller groups comprising less than $1.0 \%$ of all participants were classified as "other administrative and managerial workers." Within the "professional and engineering workers" group, smaller groups comprising less than $1.0 \%$ of all participants were classified as "other specialist professionals." Within the "transport and machine operation workers" group, smaller groups consisting of less than $1.0 \%$ of all participants including stationary and construction machinery operators were integrated into a category for "other transport workers." Forestry and fishery workers were unified in the same group. Carrying, cleaning, and packaging workers were also unified in the same group. Finally, the occupations were categorized into 39 groups. Partners' occupation (mothers' occupation) was classified into two groups: "12 major groups of workers (above mentioned)" vs "full-time homemaker," "student and graduate student," "unemployed," and "workers not otherwise classifiable."

\section{Statistical analysis}

Logistic regression analysis was performed to examine the association between working conditions (workhours, 
shift work, and occupation) and dietary behaviors (skipping breakfast, eating out, eating instant food, overeating, and eating fast), using "less than $40 \mathrm{~h}$ per week" for workhours, "no" for shift work, and "management government officials" for occupation, as the reference categories, respectively. All the final models were adjusted for age, household income, educational level (fathers' educational level), partners' age (mothers' age), partners' educational level (mothers' educational level), partners' occupation (mothers' occupation), and working conditions (workhours and/or shift work and/or occupations). All analyses were conducted using Stata/IC 14.0.

\section{Results}

\section{Workhours and shift work by occupation}

The characteristics of the study participants are shown in Table 1. Data on the workhours and the presence of shift work, by occupation, are shown in Table 2 . The mean workhours per week were longer among doctors $(68.0 \pm 17.9 \mathrm{~h} /$ week $)$, teachers $(59.2 \pm 14.4 \mathrm{~h} /$ week $)$, food and drink preparatory workers $(62.4 \pm 15.4 \mathrm{~h} /$ week), judicial police staff such as police officers $(59.7 \pm 16.4 \mathrm{~h} /$ week), and motor vehicle drivers (63.5 $\pm 17.2 \mathrm{~h} /$ week). Shift work was more commonly observed among doctors $(68.2 \%)$, nurses $(85.7 \%)$, care service workers (65.5\%), judicial police staff such as police officers (86.1\%), and other public security workers, such as firefighters (78.5\%). The mean frequency of shift work was much higher among merchandise sales workers $(12.9 \pm$ 8.0 times/month), food and drink preparatory workers $(15.0 \pm 9.0$ times/month), customer service workers $(13.9 \pm 6.7$ times/month), forestry workers and fishery workers (16.6 \pm 8.1 times/month), and motor vehicle drivers (13.9 \pm 7.4 times/month).

\section{Workhours/shift work and dietary behaviors}

Table 3 shows the associations of workhours/shift work with dietary behaviors. After adjusting for age, income, education, occupation, partners' age, partners' education, partners' occupation, and shift work, men who worked more than $65 \mathrm{~h} /$ week showed significantly higher odds ratios (ORs) for the various dietary behaviors than men who worked $40 \mathrm{~h} /$ week or less [skipping breakfast, OR 1.48 (95\% confidence interval [CI] 1.38-1.60); eating out, OR 1.31 (95\% CI 1.22-1.42); eating instant food, OR 1.38 (95\% CI 1.28-1.48); overeating, OR 1.27 (95\% CI 1.18-1.38); and eating fast, OR 1.10 (95\% CI 1.021.19)]. The $P$ trends for the odds of dietary behaviors according to the workhours were significant across the five indicators of dietary behaviors. With increasing workhours, the likelihood of skipping breakfast, eating out, eating instant food, overeating ( $\mathrm{P}$ for trend $<0.001$ ), and eating fast ( $\mathrm{P}$ for trend $=0.015$ ) increased, after adjusting for potential confounding factors. Regarding eating fast, only those who worked more than 65 workhours per week showed a significantly higher OR after adjusting for potential confounding factors.

After adjusting for age, income, education, occupation, partners' age, partners' education, partners' occupation, and workhours, men who had shift work more than 8 times per month showed significantly higher ORs for various dietary behaviors than those who did not have shift work [skipping breakfast, OR 1.79 (95\% CI1.671.92); eating out, OR1.16 (95\% CI 1.09-1.25); eating instant food, OR 1.69 (95\% CI 1.58-1.82)]. As the frequency of shift work increased, the likelihood of skipping breakfast, eating out, and eating instant food increased ( $\mathrm{P}$ for trend $<0.001$ ), after adjustment for potential confounding factors. There was no significant OR for overeating and eating fast after adjustment for potential confounding factors.

\section{Occupations characterized by workhours/shift work and related dietary behaviors}

Table 4 shows the association between dietary behaviors and the occupations characterized by long workhours and/or shift work. In some cases, although there were significant associations in the models adjusted for age, income, education, partners' age, partners' education, and partner's occupation (hereafter called model 2), the statistical significance disappeared in the models adjusted for workhours and shift work in addition to other potential confounders (hereafter called model 3). Doctors, nurses, care service workers, customer service workers, and forestry and fishery workers showed higher odds of eating instant food, while the significant associations disappeared in model 3. Similarly, judicial police staff showed significantly higher odds of skipping breakfast, eating instant food, and overeating in model 2; this was not observed in model 3. Merchandise sales workers showed significantly higher odds of overeating; this was not observed in model 3. The significantly higher odds of skipping breakfast among doctors as seen in model 2 also disappeared in model 3. Some cases showed significant associations in model 3 rather than in model 2. In model 3, other public security workers, such as firefighters, showed lower odds of skipping breakfast and eating out; this was not observed in model 2.

\section{Occupation and dietary behaviors}

Several occupations showed specific dietary behaviors even after adjusting for time-related work factors (model 3). For example, compared with management government officials, teachers were less likely to eat outside [OR 0.65 (95\% CI, 0.53-0.80)] and eat instant food [OR 0.66 (95\% CI, 0.53-0.81)], while they were more likely to eat quickly [OR 1.25 (95\% CI, 1.01-1.55)]. Care service workers showed a greater likelihood of skipping breakfast [OR 1.84 
Table 1 Characteristics of the study participants $(N=39,315)$

\begin{tabular}{|c|c|c|}
\hline & Mean & SD \\
\hline Age (fathers' age) & 32.9 & 5.7 \\
\hline Educational level & $n$ & $\%$ \\
\hline Junior high school & 1969 & 5.0 \\
\hline High school & 14,018 & 35.7 \\
\hline Higher professional school & 822 & 2.1 \\
\hline Professional school & 7629 & 19.4 \\
\hline Junior college & 846 & 2.2 \\
\hline University & 11,993 & 30.5 \\
\hline Graduate school & 2038 & 5.2 \\
\hline \multicolumn{3}{|l|}{ Household income } \\
\hline$<2$ million yen & 1657 & 4.2 \\
\hline 2.0-3.9 million yen & 13,223 & 33.6 \\
\hline 4.0-5.9 million yen & 13,416 & 34.1 \\
\hline 6.0-7.9 million yen & 6572 & 16.7 \\
\hline 8.0-9.9 million yen & 2746 & 7.0 \\
\hline 10-11.9 million yen, & 1001 & 2.6 \\
\hline 12-14.9 million yen & 382 & 1.0 \\
\hline 15-19.9 million yen & 216 & 0.6 \\
\hline$\geq 20$ million yen & 102 & 0.3 \\
\hline \multicolumn{3}{|l|}{ Breakfast eating } \\
\hline Everyday & 20,770 & 52.8 \\
\hline Not everyday & 18,545 & 47.2 \\
\hline \multicolumn{3}{|l|}{ Eating outside } \\
\hline$\leqq 3$ times/month & 16,789 & 42.7 \\
\hline$\geqq$ once/week & 22,526 & 57.3 \\
\hline \multicolumn{3}{|l|}{ Instant food eating } \\
\hline$\leqq 3$ times/month & 20,555 & 52.3 \\
\hline$\geqq$ once /week & 18,760 & 47.7 \\
\hline \multicolumn{3}{|l|}{ Eating over } \\
\hline No & 11,341 & 28.9 \\
\hline Yes & 27,974 & 71.2 \\
\hline \multicolumn{3}{|l|}{ Eating fast } \\
\hline Normal to too slow & 12,859 & 32.7 \\
\hline Too fast to slightly fast & 26,456 & 67.3 \\
\hline \multirow[t]{2}{*}{ Partners' age (mothers' age) } & 31.1 & 4.9 \\
\hline & $n$ & $\%$ \\
\hline
\end{tabular}

Partners' educational level (mothers' education)

Junior high school
High school
Higher professional school
Professional school
Junior college
University
Graduate school

$\begin{array}{ll}1411 & 3.6 \\ 11,557 & 29.4 \\ 644 & 1.6 \\ 9207 & 23.4 \\ 7080 & 18.0 \\ 8768 & 22.3 \\ 648 & 1.7\end{array}$

Table 1 Characteristics of the study participants $(N=39,315)$ (Continued)

\begin{tabular}{lll}
\hline Partners' occupation (mothers' occupation) & & \\
Administrative and managerial workers & 224 & 0.6 \\
Professional and engineering workers & 9637 & 24.5 \\
Clerical workers & 6889 & 17.5 \\
Sales workers & 2139 & 5.4 \\
Service workers & 5658 & 14.4 \\
Security workers & 116 & 0.3 \\
Agricultural, forestry, and fishery workers & 160 & 0.4 \\
Manufacturing process workers & 1356 & 3.5 \\
Transport and machine operation workers & 76 & 0.2 \\
Construction and mining workers & 30 & 0.1 \\
Carrying, cleaning packaging, and related workers & 163 & 0.4 \\
Full-time homemaker & 10,922 & 27.8 \\
Student, graduate student & 155 & 0.4 \\
Unemployed & 1214 & 3.1 \\
Workers not otherwise classifiable & 576 & 1.5 \\
\hline
\end{tabular}

$S D$ standard deviation

(95\% CI, 1.47-2.30)] and overeating [OR 1.38 (95\% CI, $1.09-1.75)$ ], while they were less likely to eat outside [OR 0.65 (95\% CI, 0.52-0.81)]. Food and drink preparatory workers were more likely to skip breakfast [OR 3.21 (95\% CI, 2.56-4.04)] and eat fast [OR 1.35 (95\% CI, 1.07-1.69)], while they were less likely to eat instant food [OR 0.71 (95\% CI, 0.57-0.88)]. Other public security workers, such as firefighters, were less likely to skip breakfast [OR 0.65 (95\% CI, 0.51-0.83)] and eat outside [OR 0.71 (95\% CI, $0.56-0.90)$ ] and more likely to eat instant food [OR 1.29 (95\% CI, 1.02-1.63)]. Motor vehicle drivers tended to skip breakfast [OR 2.27 (95\% CI, 1.81-2.83)], eat instant food [OR 1.58 (95\% CI, 1.28-1.95)], and overeat [OR 1.28 (95\% CI, 1.02-1.60)].

\section{Discussion}

The present study revealed that workhours and shift work were independently associated with dietary behaviors. Long workhours were positively associated with poor dietary behaviors in various aspects of eating: skipping breakfast, eating out, eating instant food, overeating, and eating fast. The frequency of shift work was also associated with poor dietary behaviors in some aspects of eating: skipping breakfast, eating out, and eating instant food more frequently. Some occupations characterized by long workhours and/or shift work tended to have specific dietary behaviors. After adjusting for workhours and shift work, in addition to other potential confounding factors, some associations remained significant while others became insignificant. 
Table 2 Workhours and shift work according to occupations ( $N=39,315)$

\begin{tabular}{|c|c|c|c|c|c|c|c|}
\hline & \multirow{3}{*}{$n$} & \multicolumn{2}{|c|}{ Workhours } & \multicolumn{4}{|c|}{ Shift work } \\
\hline & & \multirow[t]{2}{*}{ Mean } & \multirow[t]{2}{*}{ SD } & \multicolumn{2}{|c|}{ Shift workers } & \multirow[t]{2}{*}{ Mean } & \multirow[t]{2}{*}{ SD } \\
\hline & & & & $n$ & $\%$ & & \\
\hline Total subjects & 39,315 & 52.8 & 12.8 & 8867 & 22.6 & 9.7164 & 6.0 \\
\hline \multicolumn{8}{|l|}{ Occupations } \\
\hline \multicolumn{8}{|l|}{ Administrative and managerial workers } \\
\hline Management government officials & 590 & 48.3 & 10.4 & 60 & 10.2 & 7 & 5.6 \\
\hline Officers of companies and organizations & 396 & 58.5 & 16.4 & 37 & 9.3 & 10 & 8.4 \\
\hline Other administrative and managerial workers & 699 & 53.9 & 12.8 & 81 & 11.6 & 10 & 7.9 \\
\hline \multicolumn{8}{|l|}{ Professional and engineering workers } \\
\hline Researchers & 487 & 50.9 & 10.1 & 16 & 3.3 & 4 & 2.7 \\
\hline Manufacturing engineers & 2354 & 50.5 & 9.7 & 507 & 21.5 & 12 & 4.4 \\
\hline Architects, civil engineers, and surveyors & 1652 & 55.9 & 11.7 & 95 & 5.8 & 10 & 9.2 \\
\hline Data processing and communication engineers & 911 & 49.4 & 9.0 & 78 & 8.6 & 8 & 6.7 \\
\hline Other engineers & 1110 & 51.5 & 10.1 & 128 & 11.5 & 8 & 5.9 \\
\hline Doctors & 402 & 68.0 & 17.9 & 274 & 68.2 & 6 & 5.2 \\
\hline Nurses & 481 & 46.8 & 8.8 & 412 & 85.7 & 7 & 3.1 \\
\hline Medical technicians & 722 & 47.7 & 9.0 & 186 & 25.8 & 4 & 3.3 \\
\hline Social welfare specialist professionals & 538 & 46.7 & 8.5 & 248 & 46.1 & 6 & 3.5 \\
\hline Teachers & 1246 & 59.2 & 14.4 & 34 & 2.7 & 11 & 8.5 \\
\hline Other specialist professionals & 2509 & 51.1 & 12.5 & 322 & 12.8 & 8 & 6.5 \\
\hline \multicolumn{8}{|l|}{ Clerical workers } \\
\hline General clerical workers & 1945 & 47.0 & 8.6 & 122 & 6.3 & 6 & 6.4 \\
\hline Sales clerks & 674 & 53.8 & 11.4 & 32 & 4.7 & 6 & 7.0 \\
\hline Other clerical workers & 1246 & 49.0 & 9.8 & 144 & 11.6 & 8 & 6.0 \\
\hline \multicolumn{8}{|l|}{ Sales workers } \\
\hline Merchandise sales workers & 1416 & 54.7 & 12.4 & 137 & 9.7 & 13 & 8.0 \\
\hline Sales workers & 2721 & 57.1 & 11.6 & 89 & 3.3 & 10 & 8.8 \\
\hline Other sales workers & 270 & 53.6 & 12.9 & 25 & 9.3 & 10 & 9.4 \\
\hline \multicolumn{8}{|l|}{ Service workers } \\
\hline Care service workers & 956 & 45.8 & 9.5 & 626 & 65.5 & 6 & 3.6 \\
\hline Food and drink preparatory workers & 1007 & 62.4 & 15.4 & 118 & 11.7 & 15 & 9.0 \\
\hline Customer service workers & 1026 & 53.4 & 12.9 & 357 & 34.8 & 14 & 6.7 \\
\hline Other service workers & 1342 & 55.4 & 13.1 & 288 & 21.5 & 10 & 6.5 \\
\hline \multicolumn{8}{|l|}{ Security workers } \\
\hline Self-defense officials & 454 & 47.5 & 13.8 & 241 & 53.1 & 4 & 3.1 \\
\hline Judicial police staff, such as police officers & 628 & 59.7 & 16.4 & 541 & 86.1 & 7 & 4.3 \\
\hline Other public security workers, such as firefighters & 641 & 57.2 & 18.5 & 503 & 78.5 & 10 & 2.7 \\
\hline \multicolumn{8}{|l|}{ Agricultural, forestry, and fishery workers } \\
\hline Agriculture workers & 403 & 56.3 & 14.4 & 12 & 3.0 & 12 & 10.4 \\
\hline Forestry workers and fishery workers & 261 & 51.5 & 14.6 & 24 & 9.2 & 17 & 8.1 \\
\hline \multicolumn{8}{|l|}{ Manufacturing process workers } \\
\hline Product manufacturing and processing workers & 2983 & 48.6 & 9.3 & 1441 & 48.3 & 12 & 4.1 \\
\hline Machine maintenance and repair workers & 732 & 51.1 & 11.3 & 128 & 17.5 & 12 & 5.9 \\
\hline Other manufacturing process workers & 1623 & 48.5 & 9.7 & 690 & 42.5 & 12 & 4.2 \\
\hline
\end{tabular}


Table 2 Workhours and shift work according to occupations ( $N=39,315)$ (Continued)

\begin{tabular}{|c|c|c|c|c|c|c|c|}
\hline & \multirow{3}{*}{$n$} & \multicolumn{2}{|c|}{ Workhours } & \multicolumn{4}{|c|}{ Shift work } \\
\hline & & \multirow[t]{2}{*}{ Mean } & \multirow[t]{2}{*}{ SD } & \multicolumn{2}{|c|}{ Shift workers } & \multirow[t]{2}{*}{ Mean } & \multirow[t]{2}{*}{ SD } \\
\hline & & & & $n$ & $\%$ & & \\
\hline \multicolumn{8}{|l|}{ Transport and machine operation workers } \\
\hline Motor vehicle drivers & 1111 & 63.5 & 17.2 & 246 & 22.1 & 14 & 7.4 \\
\hline Other transport workers & 536 & 50.9 & 13.7 & 292 & 54.5 & 12 & 5.8 \\
\hline \multicolumn{8}{|l|}{ Construction and mining workers } \\
\hline Construction workers & 778 & 54.3 & 11.4 & 36 & 4.6 & 10 & 9.3 \\
\hline Electric construction workers & 601 & 54.8 & 13.2 & 96 & 16.0 & 8 & 8.2 \\
\hline Civil engineering workers & 569 & 51.9 & 9.5 & 49 & 8.6 & 12 & 9.1 \\
\hline Other construction and mining workers & 745 & 54.1 & 11.0 & 57 & 7.7 & 9 & 9.1 \\
\hline \multicolumn{8}{|l|}{ Carrying, cleaning packaging, and related workers } \\
\hline Carrying workers, cleaning workers, and packaging workers & 550 & 53.3 & 14.1 & 95 & 17.3 & 13 & 7.7 \\
\hline
\end{tabular}

$S D$ standard deviation

Time-related restrictions may result in specific dietary behaviors, such as missing meals (e.g., skipping breakfast), taking lesser time to eat (overeating, eating fast), and preparing meals in shorter durations (eating out, eating instant food). Very few studies have examined the association between workhours and dietary behaviors, such as eating breakfast and eating between meals [18]. Data on other dietary indicators according to workhours are sparse. This study presented clear evidence on the associations between workhours and dietary behaviors, using detailed classifications of workhours and various dietary indicators, with a large number of study participants. With increasing workhours, the trends of skipping breakfast, eating out, and eating instant food seemed to increase. Overeating and eating fast were also positively associated with workhours to some extent. These results suggest that long workhours lead to poor dietary behaviors, through missed meals, shorter times taken to eat, and shorter times taken to prepare meals.

However, regarding shift work, the same trends were not always observed. The frequency of shift work was not positively associated with overeating and eating fast but was positively associated with skipping breakfast, eating out, and eating instant food. Shift workers have been well-known to have irregular eating patterns [6], and our study's findings confirm this. A novel finding of our study is that we found no positive association between the frequency of shift work and the manner of eating, namely, taking a shorter time to eat. Shift workers may consume meals in a calm manner, provided they have enough time to take a break. Given this evidence, it is possible that having long workhours, rather than shift work, was more strongly linked to poor dietary behaviors in our study.

This study also evaluated trends of dietary behaviors across occupations characterized by long workhours and shift work. In some cases, the observed significant associations between occupations and dietary behaviors disappeared after adjusting for workhours and shift work in addition to other potential confounding factors, suggesting that long workhours/shift work could affect dietary behaviors. Doctors, nurses, care service workers, customer service workers, judicial police staff, and forestry and fishery workers, for example, may be less likely to eat instant food provided they have enough time for meals. In other cases, the associations remained significant after adjusting for workhours and shift work in addition to other potential confounding factors. These findings may be explained through factors influenced by the occupations, such as food environment. For example, teachers, food and drink preparatory workers, and other public security workers such as firefighters showed good dietary behaviors in certain aspects, although they also reported one or more poor dietary behaviors. One possibility is that workplace food environments are well-developed in such occupational groups.

In workplaces such as schools, teachers may utilize the lunch system or cook their own meals. Accordingly, teachers showed a lower likelihood of eating instant food and eating outside. Our previous study reported higher intakes of dairy products and calcium among teachers [19], also lending support to the contribution of school lunch to dietary behaviors. In contrast, a poor food environment in the workplace, as well as work situation, may contribute to poor dietary behaviors; for example, motor vehicle drivers demonstrated a higher likelihood of skipping breakfast, eating instant food, and overeating, which may be due to poor food availability and accessibility along their driving route and traffic situations.

Overall, shorter workhours and/or reduced shift frequency may improve dietary behaviors. Improving other factors influenced by occupation, including food 


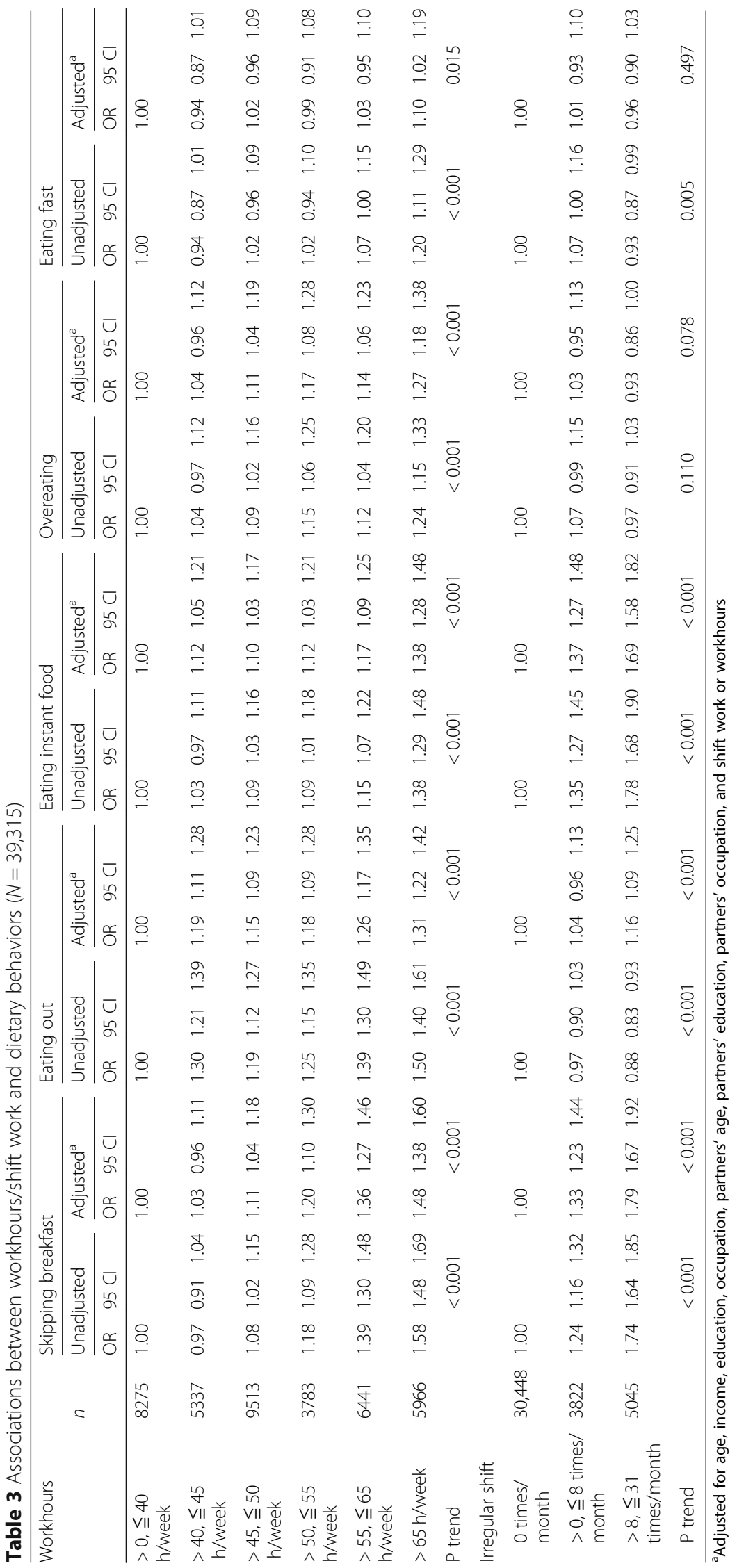




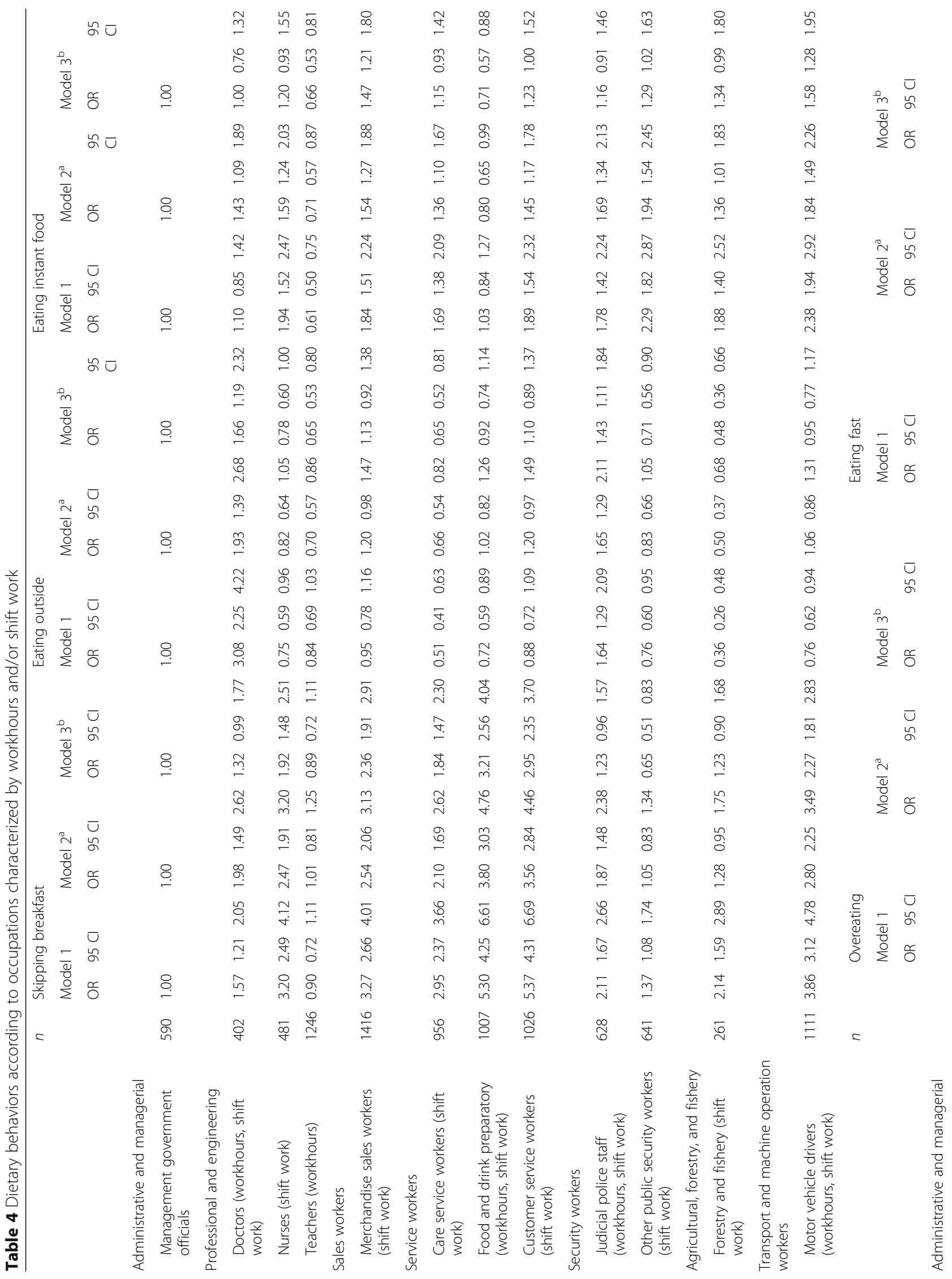


Kanaka et al. Environmental Health and Preventive Medicine $\quad$ (2018) 23:62

Page 10 of 12

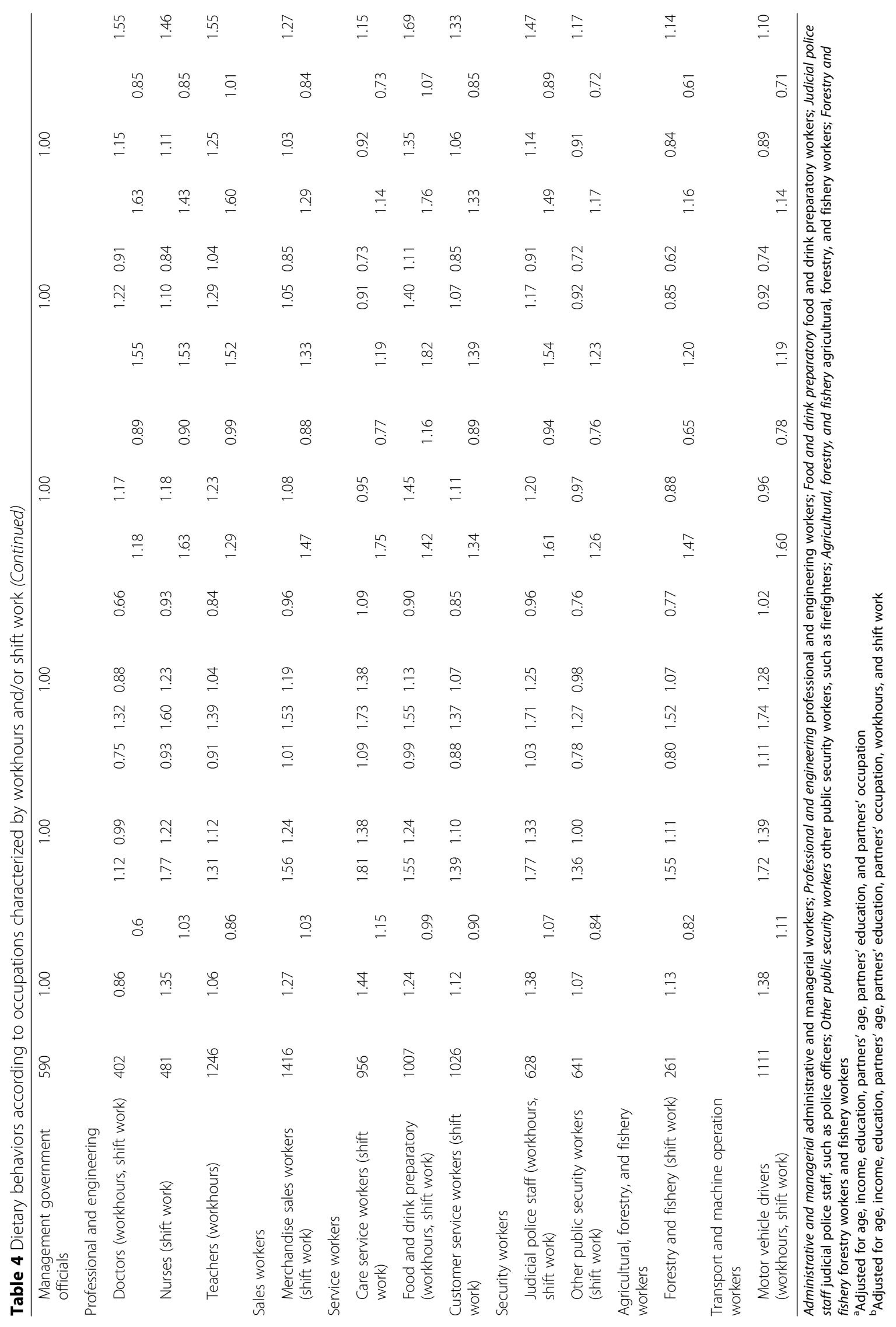


environment in the workplace, may also lead to favorable dietary behaviors; providing enough time and space and serving healthy food and drink in the workplace are important. If a reduction in shift work is not foreseen, at least an effort to improve the food environment through healthier food and drink options in workplace cafeterias and vending machines can be beneficial for the workers' health. In previous studies, the presence of cafeterias $[20,21]$ and vending machines [20] was associated with workers' diets. Workers can learn healthy diet choices through the use of such food facilities if they provide healthy food and drinks. Monitoring time-related factors and dietary behaviors at each workplace, as well as developing food environment and nutrition education [22] for workers as a public health action, would also be beneficial to promote workers' health.

\section{Limitation}

This study has several limitations that should be acknowledged. First, the study sample comprised only expectant fathers. Their dietary behaviors may be affected by their partners' pregnancy, encouraging them to change their health-related behaviors. In addition, our participants may be more interested in health and have higher levels of knowledge on the same. Therefore, it may be difficult to generalize the results of this study directly. Second, the analysis was performed using data from self-reported questionnaires, suggesting that overor underreporting should be considered in interpreting the results. In addition to time spent eating, sleeping time and resting times may be influenced by time-related factors and affect health problems; information on such lifestyle factors should also be assessed by the questionnaires. Third, our results showed simple associations between working conditions and dietary behaviors due to the cross-sectional study design. Detailed data on the causal mechanisms of the findings remain unclear; further longitudinal studies may be helpful in clarifying them. Additionally, the present study did not assess food quality and meal timing, energy balance, and nutrient intakes, which should be considered according to work schedule. Fourth, the questionnaire did not distinguish between paid and unpaid work among self-employed individuals, which might have an impact on dietary behaviors. Finally, future studies should evaluate women's diets according to occupation given the increasing number of employed women in Japan [23]. In light of women's social progress, the impact of time-related work factors would be greater.

\section{Conclusion}

In summary, this study examined the associations between time-related work factors and dietary behaviors among male workers in Japan. Both longer workhours and having shift work were associated with more frequently skipping breakfast, eating out, and eating instant food after adjusting for potential confounders. The likelihoods of overeating and eating fast were also higher among those who worked long hours. Several occupations involving long workhours and/or shift works showed specific dietary behaviors, some of which were changed after the adjustment of workhours and shift work, in addition to other potential confounding factors. Time-related work factors, as well as other factors influenced by occupation, may have a variable impact on workers' dietary behaviors.

\section{Abbreviations \\ JECS: Japan Environment and Children's Study}

\section{Acknowledgements}

We would like to thank the study participants and members of the Japan Environment and Children's Study (JECS) as of 2017 (principal investigator, Toshihiro Kawamoto): Hirohisa Saito (National Center for Child Health and Development, Tokyo, Japan), Reiko Kishi (Hokkaido University, Sapporo, Japan), Nobuo Yaegashi (Tohoku University, Sendai, Japan), Koichi Hashimoto (Fukushima Medical University, Fukushima, Japan), Chisato Mori (Chiba University, Chiba, Japan), Shuichi Ito (Yokohama City University, Yokohama, Japan), Zentaro Yamagata (University of Yamanashi, Chuo, Japan), Hidekuni Inadera (University of Toyama, Toyama, Japan), Michihiro Kamijima (Nagoya City University, Nagoya, Japan), Takeo Nakayama (Kyoto University, Kyoto, Japan), Hiroyasu Iso (Osaka University, Suita, Japan), Masayuki Shima (Hyogo College of Medicine, Nishinomiya, Japan), Yasuaki Hirooka (Tottori University, Yonago, Japan), Narufumi Suganuma (Kochi University, Nankoku, Japan), Koichi Kusuhara (University of Occupational and Environmental Health, Kitakyushu, Japan), and Takahiko Katoh (Kumamoto University, Kumamoto, Japan).

\section{Funding}

The Japan Environment and Children's Study was funded by the Ministry of the Environment, Japan. The findings and conclusions of this study are the sole responsibility of the authors and do not represent the official views of the Japanese Government.

\section{Availability of data and materials}

The data used to derive our conclusions are unsuitable for public deposition due to ethical restrictions and specific legal framework in Japan. It is prohibited by the Act on the Protection of Personal Information (Act No. 57 of 30 May 2003, amended on 9 September 2015) to publicly deposit data containing personal information. The Ethical Guidelines for Epidemiological Research enforced by the Japan Ministry of Education, Culture, Sports, Science and Technology and the Ministry of Health, Labor and Welfare also restrict the open sharing of the epidemiologic data. All inquiries about access to data should be sent to jecs-en@nies.go.jp. The person responsible for handling inquiries sent to this e-mail address is Dr. Shoji F. Nakayama, JECS Programme Office, National Institute for Environmental Studies.

\section{Authors' contributions}

RT, MT, and TK contributed to the study conception and design. MT and TK collected the data. RT and MT analyzed the data. RT wrote the paper. MT, KK, and TK critically reviewed the manuscript and supervised the study process. All authors read and approved the final manuscript.

\section{Ethics approval and consent to participate}

The JECS was approved by the Institutional Review Board of the Japan National Institute for Environmental Studies (Approval number: 2017-002) and the Ethics Committees of all participating institutions. The study was conducted in accordance with the Declaration of Helsinki and other national regulations. Written informed consent was obtained from all study participants. 


\section{Consent for publication}

Not applicable

\section{Competing interests}

The authors declare that they have no competing interests.

\section{Publisher's Note}

Springer Nature remains neutral with regard to jurisdictional claims in published maps and institutional affiliations.

\section{Author details}

'Department of Environmental Health, School of Medicine, University of Occupational and Environmental Health, 1-1 Iseigaoka, Yahatanishi-ku, Kitakyushu, Fukuoka 807-8555, Japan. ${ }^{2} J a p a n$ Environment and Children's Study, UOEH Subunit Center, University of Occupational and Environmental Health, 1-1 Iseigaoka, Yahatanishi-ku, Kitakyushu, Fukuoka 807-8555, Japan. ${ }^{3}$ Department of Pediatrics, School of Medicine, University of Occupational and Environmental Health, 1-1 Iseigaoka, Yahatanishi-ku, Kitakyushu, Fukuoka 807-8555, Japan

Received: 27 August 2018 Accepted: 29 November 2018

Published online: 14 December 2018

\section{References}

1. Grundy A, Cotterchio M, Kirsh VA, Nadalin V, Lightfoot N, Kreiger N. Rotating shift work associated with obesity in men from northeastern Ontario. Health Promot Chronic Dis Prev Can. 2017;37(8):238-47.

2. Lu YC, Wang CP, Yu TH, Tsai IT, Hung WC, Lu IC, et al. Shift work is associated with metabolic syndrome in male steel workers-the role of resistin and WBC count-related metabolic derangements. Diabetolo Metab Syndr. 2017;9:83.

3. Sokejima S, Kagamimori S. Working hours as a risk factor for acute myocardial infarction in Japan: case-control study. BMJ. 1998;317(7161): 775-80.

4. Lappalainen R, Saba A, Holm L, Mykkanen H, Gibney MJ, Moles A. Difficulties in trying to eat healthier: descriptive analysis of perceived barriers for healthy eating. Eur J Clin Nutr. 1997;51(Suppl 2):S36-40.

5. Escoto KH, Laska MN, Larson N, Neumark-Sztainer D, Hannan PJ. Workhours and perceived time barriers to healthful eating among young adults. Am J Health Behav. 2012;36(6):786-96.

6. Lowden A, Moreno C, Holmback U, Lennernas M, Tucker P. Eating and shift work - effects on habits, metabolism and performance. Scand J Work Environ Health. 2010;36(2):150-62

7. Mota MC, De-Souza DA, Rossato LT, Silva CM, Araujo MB, Tufik S, et al. Dietary patterns, metabolic markers and subjective sleep measures in resident physicians. Chronobiol Int. 2013;30(8):1032-41.

8. Han K, Choi-Kwon S, Kim KS. Poor dietary behaviors among hospital nurses in Seoul, South Korea. Appl Nurs Res. 2016;30:38-44.

9. Fukuda $Y$, Nakamura $K$, Takano T. Accumulation of health risk behaviours is associated with lower socioeconomic status and women's urban residence: a multilevel analysis in Japan. BMC Public Health. 2005;5:53.

10. Lin W, Hang CM, Yang HC, Hung MH. 2005-2008 Nutrition and Health Survey in Taiwan: the nutrition knowledge, attitude and behavior of 19-64 year old adults. Asia Pac J Clin Nutr. 2011;20(2):309-18.

11. Okada E, Takahashi K, Takimoto H, Takabayashi S, Kishi T, Kobayashi T, et al. Dietary patterns among Japanese adults: findings from the National Health and Nutrition Survey, 2012. Asia Pac J Clin Nutr. 2018;27(5):1120-30.

12. Michikawa T, Nitta H, Nakayama SF, Yamazaki S, Isobe T, Tamura K, et al. Baseline profile of participants in the Japan Environment and Children's Study (JECS). J Epidemiol. 2018;28(2):99-104.

13. Kawamoto T, Nitta H, Murata K, Toda E, Tsukamoto N, Hasegawa M, et al. Rationale and study design of the Japan Environment and Children's Study (JECS). BMC Public Health. 2014;14:25.

14. Michikawa T, Nitta H, Nakayama SF, Ono M, Yonemoto J, Tamura K, et al. The Japan Environment and Children's Study (JECS): a preliminary report on selected characteristics of approximately 10000 pregnant women recruited during the first year of the study. J Epidemiol. 2015;25(6):452-8.

15. Yokoyama Y, Takachi R, Ishihara J, Ishii Y, Sasazuki S, Sawada N, et al. Validity of short and long self-administered food frequency questionnaires in ranking dietary intake in middle-aged and elderly Japanese in the Japan
Public Health Center-Based Prospective Study for the Next Generation (JPHC-NEXT) protocol area. J Epidemiol. 2016;26(8):420-32.

16. Communications MolAa. Japan Standard Occupational Classification (Rev. 5th, December 2009) General Principles for the Japan Standard Occupational Classification [Available from: http://www.soumu.go.jp/ english/dgpp_ss/seido/shokgyou/co09-2.htm. Accessed 17 Apr 2018.

17. Communications MolAa. Japan Standard Occupational Classification (Rev. 5th, December 2009) Structure and Explanatory Notes [Available from: http://www.soumu.go.jp/english/dgpp_ss/seido/shokgyou/co09-4.htm. Accessed 17 Apr 2018.

18. van der Hulst M. Long workhours and health. Scand J Work Environ Health. 2003;29(3):171-88

19. Tanaka R, Tsuji M, Senju A, Kusuhara K, Kawamoto T. Dietary differences in male workers among smaller occupational groups within large occupational categories: findings from the Japan Environment and Children's Study (JECS). Int J Environ Res Public Health. 2018;15(5). https://doi.org/10.3390/ ijerph15050961.

20. Almeida FA, Wall SS, You W, Harden SM, Hill JL, Krippendorf BE, et al. The association between worksite physical environment and employee nutrition, and physical activity behavior and weight status. J Occup Environ Med. 2014;56(7):779-84.

21. Roos E, Sarlio-Lahteenkorva S, Lallukka T. Having lunch at a staff canteen is associated with recommended food habits. Public Health Nutr. 2004;7(1): 53-61.

22. Geaney F, Kelly C, Greiner BA, Harrington JM, Perry IJ, Beirne P. The effectiveness of workplace dietary modification interventions: a systematic review. Prev Med. 2013;57(5):438-47.

23. Statistics Bureau MolAaC. Monthly results -August 2018-Summary Tables, Time series. Table 2 Population aged 15 years old and over by labour force status 2018 [Released on September 28, 2018]. Available from: http://www. stat.go.jp/english/data/roudou/results/month/index.html. Accessed 17 Oct 2018.

Ready to submit your research? Choose BMC and benefit from:

- fast, convenient online submission

- thorough peer review by experienced researchers in your field

- rapid publication on acceptance

- support for research data, including large and complex data types

- gold Open Access which fosters wider collaboration and increased citations

- maximum visibility for your research: over $100 \mathrm{M}$ website views per year

At BMC, research is always in progress.

Learn more biomedcentral.com/submissions 